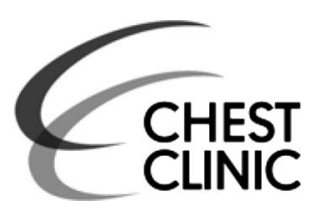
CLINIT

${ }^{1}$ Centre for Translational Inflammation Research, University of Birmingham, Birmingham, UK

${ }^{2}$ Department of Respiratory Medicine, Heart of England NHS Foundation Trust, Birmingham, UK

${ }^{3}$ Department of Respiratory Medicine, Nottingham University Hospitals NHS Trust, Nottingham, UK

${ }^{4}$ British Thoracic Society, London, UK

${ }^{5}$ Department of Respiratory Medicine, North Bristol NHS Trust, Bristol, UK

\section{Correspondence to}

Dr JM Calvert, Department of Respiratory Medicine, North Bristol NHS Trust, Bristol, UK; james.calvert@nbt.nhs.uk

Received 22 January 2015 Revised 14 February 2015 Accepted 20 March 2015 Published Online First 21 July 2015

\title{
A care-bundles approach to improving standard of care in AECOPD admissions: results of a national project
}

\author{
AM Turner, ${ }^{1,2}$ WS Lim, ${ }^{3}$ C Rodrigo, ${ }^{3}$ SA Welham, ${ }^{4}$ JM Calvert ${ }^{5}$
}

\begin{abstract}
This report describes a care bundles implementation project for COPD undertaken during 2013 in England and Wales. High-level data were collected on outcomes of care for 11748 patients admitted with an acute exacerbation of COPD (AECOPD). Patient-level data on processes and outcomes of care were collected on 3272 COPD admissions, among which 1174 bundles were delivered. Analysis demonstrated a statistically significant reduction in mortality and length of hospital stay from some bundle elements. Outcomes, including bundle completion rates, were better when specialist respiratory review occurred. The results support wider use of care bundles for AECOPD.
\end{abstract}

\section{INTRODUCTION}

COPD accounts for $10 \%$ of hospital medical admissions (over 90000 annually) in the UK. The number of admissions has increased by $50 \%$ in the last decade and accounts for one million bed days per annum. Despite improvements in COPD care that have occurred in hospitals over the last 10 years, wide variation remains between hospitals in the 2014 audit; in particular, the range for in-patient mortality was $0 \%-16 \% .^{1}$ Access to expert care continues to be an issue. In some centres, all COPD patients were seen by respiratory specialists, while in others, almost none received specialist care. ${ }^{1}$ There is therefore an opportunity for improving outcomes for patients by ensuring high quality care is consistently provided.

A bundle is a structured way of improving the process of care and thereby improving patient outcomes. It is a small, straightforward set of evidencebased clinical interventions or actions, which when performed reliably improves patient outcomes. The bundle resembles a list, but is a cohesive unit where all elements must be completed to achieve the best outcomes. The value of care bundles has been demonstrated in a UK setting; a fall of 18.5 points in the hospital standardised mortality occurred following bundle implementation for 13 diagnoses. ${ }^{2}$ Results of a smaller single-hospital study of a COPD discharge bundle demonstrated reduced 30-day readmission rate and improved compliance with key processes of care (eg, smoking cessation). ${ }^{3}$ This short report describes the results of an acute exacerbation of COPD (AECOPD) care bundles implementation study undertaken by the British Thoracic Society (BTS) with the support of NHS Improvement.

\section{METHODS}

Bundle content for management of AECOPD at admission and at discharge was developed by an expert panel put together by the BTS and NHS Improvement who met initially in October 2011.

The admission bundle elements were:

1. Establishing a correct diagnosis of AECOPDthis required chest X-ray (CXR) and ECG performed within $4 \mathrm{~h}$ of admission, together with a record of spirometry;

2. Assessing oxygenation and prescribing a target range within $1 \mathrm{~h}$ of admission;

3. Recognising and responding to respiratory acidosis;

4. Initiating correct treatment-this required administration of steroids, antibiotics (if appropriate) and nebulised therapy within $4 \mathrm{~h}$ of admission;

5. Review by a member of the respiratory specialist team within $24 \mathrm{~h}$ of admission.

Documentation of the following discharge bundle elements was also required:

1. Inhaler technique had been checked and medications reviewed.

2. Written self-management (SM) plan and emergency drug pack, if appropriate, were in place.

3. Smoking status and assistance to quit where appropriate.

4. Suitability for pulmonary rehabilitation (PR) had been assessed and PR offered, if appropriate.

5. Follow-up (by phone or in person) within $72 \mathrm{~h}$ of discharge.

Hospitals across England and Wales were invited to participate in the project in July 2012, gaining executive support from their board to do so. Individual Trusts determined who would deliver the bundles locally; this may have been a mixture of staff (eg, doctors, clinical nurse specialists, physiotherapists). In November 2012, project teams met and underwent training; data collection began thereafter and continued until the end of October 2013. It used standardised forms entered via the BTS audit website plus a patient-satisfaction survey. Patient-level data were similar to the national COPD audit dataset. High-level data were collected from hospital episode statistics and notes where COPD was defined as, all patients receiving an ICD-10 diagnostic code of J4144 as the primary diagnosis. Data collected (per month) included total number of COPD admissions, COPD patients discharged from emergency medicine and patients in whom a bundle was used, in-hospital mortality, length of stay (LOS) and readmission rate at 28 days. 
All data were analysed in SPSS V.21.0. Initial comparisons between patients receiving and not receiving a bundle were conducted using $\chi^{2}$ for frequency variables and Mann-Whitney for scale variables. Adjustment for centre and other covariates on admission bundle outcome was carried out using generalised estimating equations in order to adjust for clustering due to centres. The LOS data were too skewed to construct a robust linear regression; hence, a logistic model utilising the outcome of LOS <median (5 days) was used instead. Significance was taken as $\mathrm{p}<0.05$.

\section{RESULTS}

Twenty-one hospitals participated. High-level data were collected for 11748 patients and patient-level data for 3272 COPD admissions and 2263 discharges. Table 1 shows patient characteristics. The admission and discharge datasets were collected separately, albeit in the same time period; therefore, there would have been overlap, but this was not complete. For example, some Trusts already had a discharge bundle in place, so only submitted data on the admission bundle.

Admission bundle completion rates rose gradually from 1.8\% to $13.2 \%$ by the end of the project. Many patients received bundle elements even without formal use of an admission bundle; however, patients in whom a bundle was applied were more likely to have $\geq 4$ bundle elements completed $(26.8 \%$ vs $18.2 \%, \mathrm{p}=0.005)$. Univariate analysis, adjusted for centre, did not reveal any impact of a bundle on mortality $(\mathrm{p}=0.17)$ or LOS $(p=0.35)$ using outcomes derived from HES data. In multivariate analyses, adjusted for centre and gender (since this differed between patients receiving the bundle and not), several parts of the admission bundle related to the outcome. Specifically, mortality was reduced by correct use of oxygen (OR: $0.22(0.05$ to 0.88$), p=0.03)$ and treatment within $4 \mathrm{~h}$ (OR: $0.60(0.42$ to 0.87$), \mathrm{p}<0.01)$, while LOS fell below the median if acidosis and oxygen were managed properly (OR: 1.84 (1.38 to 2.46$)$ and $1.41(1.20$ to 1.67$)$, both $\mathrm{p}<0.01)$. Patients reviewed by the respiratory team at any time were more likely to receive a bundle $(17.3 \%$ vs $9.1 \%, \mathrm{p}<0.0001)$ to have the diagnosis, oxygen and acidosis elements of the bundle completed (all $\mathrm{p}<0.0001)$ and had a slightly lower death rate $(4.4 \%$ vs $6.3 \%)$ despite higher admission $\mathrm{pCO}_{2}(6.10$ vs 5.61, $\mathrm{p}<0.0001)$ and higher non-invasive ventilation (NIV) rates (61.2\% vs $44.8 \%, \mathrm{p}=0.003)$.

Discharge bundle completion rates rose gradually from $4.1 \%$ to $14.1 \%$. Again, patients in whom a bundle was applied were more likely to receive all bundle elements ( $\geq 4$ bundle elements completed $(26.8 \%$ vs $18.2 \%, p=0.005)$, see also table 1$)$. Data submitted by Trusts regarding readmission rates were patchy and insufficient to judge the effect of the bundle or its elements. Patients reviewed by the respiratory team were more likely to receive a bundle $(34.9 \%$ vs $10.8 \%, \mathrm{p}<0.0001)$ and have $\geq 4$ bundle elements completed $(28.7 \%$ vs $4.2 \%, \mathrm{p}<0.0001)$. Significance was not affected by adjustment for centre. A total of 156 patient-satisfaction questionnaires were completed; from Trusts where pre- and post-bundle implementation data were submitted, patients' self-reported ability to understand and self-

Table 1 Characteristics of the patients, care bundle receipt and bundle elements received

\begin{tabular}{|c|c|c|c|c|c|c|c|c|c|}
\hline \multicolumn{5}{|l|}{ Admission bundle $n=3272$} & \multicolumn{5}{|c|}{ Discharge bundle $n=2263$} \\
\hline & Whole group & $\begin{array}{l}\text { No bundle } \\
\mathrm{N}=2576\end{array}$ & $\begin{array}{l}\text { Bundle } \\
\mathrm{N}=515\end{array}$ & $\mathrm{p}$ Value & & $\begin{array}{l}\text { Whole } \\
\text { group }\end{array}$ & $\begin{array}{l}\text { No bundle } \\
\mathrm{N}=1547\end{array}$ & $\begin{array}{l}\text { Bundle } \\
\mathrm{N}=659\end{array}$ & p Value \\
\hline Male & $1608(49.1 \%)$ & $1346(52.3 \%)$ & $231(44.9 \%)$ & 0.002 & Male & $1088(48.2 \%)$ & $750(48.5 \%)$ & $311(47.2 \%)$ & 0.60 \\
\hline Age & $72.2(64.5-79.6)$ & $72.3(64.7-79.4)$ & $71.2(64.0-80.0)$ & 0.12 & Age & $72(64-79)$ & $72(64-79)$ & $71(65-78)$ & 0.22 \\
\hline LOS (days) & $5(2-9)$ & $5(2-9)$ & $5(2-8)$ & 0.36 & LOS (days) & $5(2-9)$ & $5(2-9)$ & $5(3-9)$ & 0.05 \\
\hline $\begin{array}{l}\text { Discharged from ED/ } \\
\text { AMU }\end{array}$ & $317(9.7 \%)$ & $245(9.5 \%)$ & $54(10.5 \%)$ & 0.50 & $\begin{array}{l}\text { Discharged from } \\
\text { ED/AMU }\end{array}$ & $184(8.6 \%)$ & $131(8.5 \%)$ & $59(9.0 \%)$ & 0.72 \\
\hline Outcome & & & & 0.72 & & & & & \\
\hline Discharged & $2391(77.7 \%)$ & 1917 (74.4\%) & $355(68.9 \%)$ & & & & & & \\
\hline EDS & $543(17.7 \%)$ & $424(16.5 \%)$ & $73(14.2 \%)$ & & & & & & \\
\hline Died & $142(4.6 \%)$ & $114(4.4 \%)$ & $24(4.7 \%)$ & & & & & & \\
\hline Diagnostic assessment & $1365(41.7 \%)$ & $1071(41.6 \%)$ & $233(45.2 \%)$ & 0.13 & Treatment bundle* & $819(36.2 \%)$ & $311(20.1 \%)$ & $490(74.4 \%)$ & $<0.01$ \\
\hline Oxygen management & $3024(92.4 \%)$ & $2384(92.5 \%)$ & $470(91.3 \%)$ & 0.32 & SM bundle* & $643(28.4 \%)$ & $198(12.8 \%)$ & $425(64.5 \%)$ & $<0.01$ \\
\hline Acidosis management & $1117(34.1 \%)$ & 872 (33.9\%) & $184(35.7 \%)$ & 0.41 & Smoking bundle* & $1673(73.9 \%)$ & $1034(66.8 \%)$ & $593(90.0 \%)$ & $<0.01$ \\
\hline Treatment within $4 \mathrm{~h}$ & $1555(47.5 \%$ & $1241(48.2 \%)$ & $231(44.9 \%)$ & 0.17 & PR bundle* & $531(23.5 \%)$ & $208(13.4 \%)$ & $310(47.0 \%)$ & $<0.01$ \\
\hline Respiratory review $<24 \mathrm{~h}$ & $1295(37.6 \%)$ & $973(37.8 \%)$ & $243(47.2 \%)$ & $<0.01$ & Follow-up contact & $1166(51.9 \%)$ & $500(32.3 \%)$ & $502(76.2 \%)$ & $<0.01$ \\
\hline Time to antibiotics (min) & $148(68-280)$ & $157(80-285)$ & $95(22-210)$ & 0.012 & $\begin{array}{l}\text { Smoking cessation } \\
\text { referral } \\
\text { Done } \\
\text { NA } \\
\text { Declined }\end{array}$ & $\begin{array}{r}120(5.5 \%) \\
1293(59.4 \%) \\
260(11.9 \%)\end{array}$ & $\begin{array}{c}57(3.7 \%) \\
851(55.0 \%) \\
126(8.1 \%)\end{array}$ & $\begin{array}{c}55(8.3 \%) \\
408(61.9 \%) \\
130(19.7 \%)\end{array}$ & $<0.01$ \\
\hline Time to resp review (h) & $17.0(7.0-36.0)$ & $17.7(7.3-39.3)$ & $15.4(7.2-47.1)$ & 0.030 & $\begin{array}{l}\text { Pulm rehab } \\
\text { Assessed } \\
\text { Referred } \\
\text { NA } \\
\text { Declined } \\
\text { Done Rehab before }\end{array}$ & $\begin{array}{l}770(34.0 \%) \\
320(14.1 \%) \\
151(6.8 \%) \\
315(13.9 \%) \\
180(8.1 \%)\end{array}$ & $\begin{array}{c}434(28.1 \%) \\
133(8.6 \%) \\
83(5.4 \%) \\
93(6.0 \%) \\
93(6.0 \%)\end{array}$ & $\begin{array}{c}336(51.0 \%) \\
178(27.0 \%) \\
65(9.9 \%) \\
192(29.1 \%) \\
85(12.9 \%)\end{array}$ & $<0.01$ \\
\hline
\end{tabular}

*'bundle' refers to the relevant element of the discharge bundle.

Data are shown as $\mathrm{n}(\%)$ or median (IQR). Significant differences between bundle and no bundle groups are highlighted by a p value in bold type. For 181 admission bundle patients and 59 discharge bundle patients, their bundle receipt status was not entered by the managing team.

$\mathrm{AMU}$, acute medical unit; ED, emergency department; EDS, early discharge scheme; LOS, length of stay; NA, not applicable; PR, pulmonary rehabilitation; SM, self-management. 
manage their COPD had improved post implementation, although low numbers of respondents limited the conclusions that could be drawn.

\section{DISCUSSION}

There was evidence that receipt of a COPD care bundle at admission was associated with significantly improved outcomes. Receipt of the oxygen component was associated with $80 \%$ lower in-patient mortality, and receipt of appropriate treatment within $4 \mathrm{~h}$ of hospital admission was associated with $40 \%$ lower in-patient mortality. Despite the fact that correlation does not equal causation in a longitudinal observational study such as this, these findings are congruent with trial evidence regarding controlled oxygen in AECOPD, which is associated with reduced mortality. ${ }^{4}$ Furthermore, receipt of either the oxygen element and/or timely NIV was associated with shorter LOS. Again, these findings are congruent with the literature showing improved outcomes with appropriate use of NIV. ${ }^{5}$ It is possible that some associations have occurred due to confounding or selection bias, as patients receiving a care bundle were almost twice as likely to have been seen by the respiratory team, and in general, those seen by respiratory were more unwell (see full report for details). Perhaps, use of a care bundle, which appeared to improve actions representative of quality care in our data, would bring non-respiratory specialists closer to achieving the improved outcomes achieved by respiratory practitioners in our dataset and elsewhere. ${ }^{1}$

The biggest impact of the discharge bundle was likely to be on readmission rates, but the only data available to assess this were derived from Trusts' hospital episode statistics. As bundles were completed in a relatively small proportion of patients discharged, it was not surprising that no effect on this outcome was seen. Nevertheless, it is encouraging to note that patient satisfaction has improved, and use of a specific discharge bundle has made it more likely that each element of quality care is received. It is notable that the difference in completion rate for individual bundle elements (eg, smoking cessation advice $12.8 \%$ vs $64.5 \%$ ) was far more marked than the receipt of $\geq 4$ elements. This may be because non-specialist teams were not able to deliver all parts; smoking cessation plan implementation and PR assessments require specific staff training to deliver properly, and follow-up phone calls require sufficient non-ward-based staff. The project was relatively short, and Trusts would not have had the time to train non-specialist ward nurses or submit and approve business cases to increase staff numbers in this time frame. The short duration of the project, in service development terms, is probably the explanation for low rates of bundle completion. Many participating Trusts reported difficulty introducing these major changes in service delivery without significant managerial or financial support, changes to job plans and/or changes to staffing levels; this was reflected by the slow start to bundle completion in most centres. Better bundle completion rates would only be achieved with Trust-sponsored training and enhanced respiratory staffing levels. Mismatch between bed base and staffing in respiratory medicine compared to admission numbers for COPD alone was highlighted in the 2014 National COPD audit. ${ }^{1}$

In conclusion, the results from this pilot are hugely encouraging and suggest that wide implementation of the BTS COPD care bundles is feasible and has the potential to impact on processes of care and important measurable clinical outcomes. However, further research is needed to confirm the findings and delineate cost-effectiveness.

Acknowledgements The authors would like to thank all Trusts who participated in the project, and their staff, for the efforts they put into data collection. We thank the Department of Health, South West Strategic Health Authority Respiratory Programme for providing some funding towards this project. We also thank the South West SHA Respiratory Leads and the team from NHS Improvement for their help and support. All staff participating are named in the full BTS report, ${ }^{6}$ wherein additional methods and results can also be seen.

Contributors JMC, WSL and SAW conceived and managed the project. AMT and CR collected the data. AMT analysed the results and drafted the manuscript.

Competing interests None.

Provenance and peer review Not commissioned; externally peer reviewed.

\section{REFERENCES}

1 Stone RA, Roberts CM, Lowe D, et al. COPD: who cares matters. National Chronic Obstructive Pulmonary Disease (COPD) Audit Programme: clinical audit of COPD exacerbations admitted to acute units in England and Wales 2014. London: Royal College of Physicians, 2015.

2 Robb E, Jarman $B$, Suntharalingam $G$, et al. Using care bundles to reduce in-hospital mortality: quantitative survey. BMJ 2010;340:c1234.

3 Hopkinson NS, Englebretsen C, Cooley N, et al. Designing and implementing a COPD discharge care bundle. Thorax 2012;67:90-2.

4 Austin MA, Wills KE, Blizzard L, et al. Effect of high flow oxygen on mortality in chronic obstructive pulmonary disease patients in prehospital setting: randomised controlled trial. BMJ 2010;341:c5462.

5 Plant PK, Owen JL, Elliott MW. Early use of non-invasive ventilation for acute exacerbations of chronic obstructive pulmonary disease on general respiratory wards: a multicentre randomised controlled trial. Lancet 2000;355:1931-5.

6 Calvert J, Lim WS, Rodrigo C, et al. British Thoracic Society Pilot Care Bundle Project: a care bundles-based approach to improving standards of care in chronic obstructive pulmonary disease and community acquired pneumonia. BTS Rep 2014;6. https://www.brit-thoracic.org.uk/audit-and-quality-improvement/bts-care-bundles-forcap-and-copd/ 